\title{
Laying hens can convert high doses of folic acid added to the feed into natural folates in eggs providing a novel source of food folate
}

\author{
Leane Hoey ${ }^{1}$, Helene McNulty ${ }^{1}$, Elizabeth M. E. McCann ${ }^{2,3}$, Kelvin J. McCracken ${ }^{3}$, John M. Scott ${ }^{4}$, \\ Barbara Blaznik Marc ${ }^{5}$, Anne M. Molloy ${ }^{5}$, Ciaren Graham ${ }^{1}$ and Kristina Pentieva ${ }^{1}$ \\ ${ }^{1}$ Northern Ireland Centre for Food and Health, University of Ulster, Coleraine BT52 1SA, UK \\ ${ }^{2}$ Agricultural, Food and Environmental Science Division, Agri-Food and Biosciences Institute, Newforge Lane, \\ Belfast BT9 5PX, UK \\ ${ }^{3}$ Queen's University, Newforge Lane, Belfast BT9 5PX, UK \\ ${ }^{4}$ School of Biochemistry and Immunology, Trinity College, Dublin 2, Republic of Ireland \\ ${ }^{5}$ School of Clinical Medicine, Trinity College, Dublin 2, Republic of Ireland
}

(Received 29 August 2007 - Revised 1 April 2008 - Accepted 7 April 2008 - First published online 23 June 2008)

There are few good sources of natural food folates apart from green leafy vegetables and these may have a limited potential to increase folate status because of substantial losses that can occur during cooking. Fortified foods can overcome this but are controversial because of safety concerns regarding chronic exposure to high-dose folic acid (FA; the synthetic form). The aim of the present study was to develop eggs with an enriched natural folate content and minimal unmetabolised FA. Forty-eight, 30-week-old laying hens were randomised to receive the basal feed (formulated to provide $1 \mathrm{mg}$ folate/ $\mathrm{kg}$ feed) to which had been added one of the following FA levels $(0,2,4,8,16,32 \mathrm{mg} / \mathrm{kg}$ feed). Total folate was measured in eggs collected throughout the 12-week study period and the FA content estimated at 12 weeks. Results showed that the maximal egg folate content was achieved by adding $16 \mathrm{mg} \mathrm{FA} / \mathrm{kg}$ feed. At this optimal dose, the total folate content per egg was $75 \mu \mathrm{g}$ (compared with $32 \mu \mathrm{g}$ in a regular egg) of which FA represented at most $10 \%$, a level which would probably be converted into natural folates by humans after ingestion. The results demonstrate that it is possible to use synthetic FA at high doses to produce novel animal foods enriched with natural folates in a costefficient process. Such foods may be particularly relevant to European populations without access to FA fortification and therefore dependent on natural food folate sources for the primary prevention of folate-related disease.

Eggs: Natural folates: Folic acid: Novel foods

The achievement of optimal folate status is an urgent public health issue because of the established role of folate in the prevention of neural tube defects ${ }^{(1,2)}$ and its potential role in the prevention of CVD, in particular stroke ${ }^{(3,4)}$, certain cancers $^{(5,6)}$, cognitive impairment ${ }^{(7,8)}$ and osteoporosis ${ }^{(9,10)}$. Diets in general do not provide an optimal folate status to protect against diseases such as neural tube defects; therefore women are recommended to increase their folate intake periconceptionally ${ }^{(11,12)}$. However, compliance with these recommendations is low ${ }^{(13,14)}$ and they have been found to be ineffective ${ }^{(12,15)}$. In contrast, mandatory folic acid (FA) fortification of cereal grains implemented in North America and elsewhere has substantially increased folate status ${ }^{(16,17)}$, reduced the occurrence of neural tube defects ${ }^{(18-20)}$ and possibly reduced stroke-related mortality ${ }^{(4,21)}$. Despite this evidence, many European governments have decided against implementing similar populationbased policies because of safety concerns regarding chronic exposure to FA, the synthetic form of the vitamin. Such concerns include the potential of high-dose FA to promote colorectal tumorigenesis in patients with pre-existing lesions ${ }^{(22-24)}$ despite the considerable evidence which supports a protective role of folate against cancer ${ }^{(5,6)}$. A further ongoing concern is that high-dose FA may potentially mask the anaemia of vitamin $\mathrm{B}_{12}$ deficiency while allowing the associated irreversible neurological symptoms to progress ${ }^{(25)}$.

As strategies to increase folate status are generally ineffective if based on health promotion and educational campaigns, or controversial if based on mandatory fortification of foods with FA, all possibilities to increase folate status in the general population to ensure protection against disease should be investigated. One such possibility is the development of novel food products enriched with folate. Previous work in this area showed that it is feasible to produce folate-enriched eggs through the addition of FA to the feed of laying hens ${ }^{(26-28)}$. Although some of these studies ${ }^{(27,28)}$ included FA doses within the range of those used in the present study, they were unclear with respect to the optimal dose and duration of FA addition required to achieve a maximal

Abbreviations: FA, folic acid; NMF, non-methyl folate.

* Corresponding author: Dr Leane Hoey, fax +44028 70323023, email 1.hoey@ulster.ac.uk 
egg folate content. More importantly, none of these studies considered whether FA added at increased amounts to the hens' feed could be converted into natural folate forms in the egg. The latter is of particular relevance given the current concerns of some authorities regarding over-exposure to highdose FA. The aim of the present study, therefore, was to identify the optimal dose of FA to be added to the feed of laying hens for the achievement of an egg with maximal total folate content, but with a minimal amount of unmetabolised FA. A secondary aim was to determine the duration of exposure of hens to the FA-enhanced feed required to produce eggs with an optimal folate content.

\section{Materials and methods}

\section{Study design}

The study was approved by the Newforge Ethical Committee and conducted under experimental licence (Animals (Scientific) Act 1986). The 12-week experiment was carried out at the Agri-Food and Biosciences Institute (Newforge Lane, Belfast, UK) and involved 30-week-old Hy-line brown laying hens. Light was provided for $16 \mathrm{~h}$ daily and temperature was maintained at $23 \pm 3^{\circ} \mathrm{C}$ throughout the experiment. Forty-eight hens were randomised to receive one of six dietary treatments ( $n 8$ hens per treatment). The treatments consisted of the basal feed which was a commercial crumbled pellet containing approximately $1 \mathrm{mg}$ folate $/ \mathrm{kg}$ feed, to which had been added the following amounts of FA $(0,2,4,8,16$ and $32 \mathrm{mg} / \mathrm{kg}$ feed). FA was added to the basal feed by spraying the feed with solution containing FA (Trouw Nutrition, Belfast, UK; $91 \%$ purity). Feed and water were supplied ad libitum and one egg per hen was collected for analysis at weeks $0,3,6$ and 12 . The shell was removed and the egg freeze-dried. Approximately $5 \mathrm{ml}$ of blood was collected from the wing vein of hens at the end of week 12 using a needle and syringe. The blood sample was centrifuged and the serum collected. Egg and serum samples were stored at $-70^{\circ} \mathrm{C}$ and samples of each dietary treatment were collected and stored at $-20^{\circ} \mathrm{C}$ until subsequent analysis of folate content.

\section{Determination of total folate content of samples}

The total folate content of egg, feed and serum samples was measured in duplicate at the University of Ulster, Coleraine by microbiological assay with Lactobacillus casei $^{(29)}$. In the case of the egg and feed samples, the microbiological assay was preceded by thermal extraction with tri-enzyme treatment ${ }^{(30)}$.

Thermal extraction with tri-enzyme treatment (for egg and feed samples). All preparative and analytical procedures were performed as originally described by Tamura $^{(30)}$ and modified by McKillop et al. ${ }^{(31)}$ with the following additional modifications. Freeze-dried egg samples were ground using a pestle and mortar and $0.2 \mathrm{~g}$ of sample was homogenised in $5 \mathrm{ml}$ 2-(cyclohexylamino)ethanesulfonic acid (CHES)/ HEPES buffer. A volume of $250 \mu \mathrm{l}$ amylase $(50 \mathrm{mg} / \mathrm{ml})$ and $100 \mu \mathrm{l}$ conjugase was added to each tube and incubated for $2 \mathrm{~h}$ at $37^{\circ} \mathrm{C}$. After thermal deactivation of the enzymes, $250 \mu \mathrm{l}$ protease $(2 \mathrm{mg} / \mathrm{ml})$ was added to each tube and incubated for $1 \mathrm{~h}$ at $37^{\circ} \mathrm{C}$. For the hen feed, a similar procedure was followed except that $1 \mathrm{~g}$ of each dietary treatment was homogenised in $10 \mathrm{ml}$ CHES/HEPES buffer, the volume of enzymes described above was doubled and amylase was prepared at a concentration of $10 \mathrm{mg} / \mathrm{ml}$.

Microbiological assay with Lactobacillus casei (for total folate content of egg, feed and serum samples). This procedure was performed as described in detail elsewhere ${ }^{(29)}$. Calibration of the microbiological assay was performed using FA (Sigma Chemical Co., Poole, Dorset, UK) as a standard. Under the conditions of the assay in our laboratory (pH 6.7 of the assay medium), L. casei showed equivalent responses to the main folate derivatives (FA, 5-methyltetrahydrofolate, 5-formyltetrahydrofolate, 10-formyltetrahydrofolate and tetrahydrofolate). For quality-control purposes, lyophilised pig liver (CRM 487; European Commission, Institute for Reference Materials and Measurements, Geel, Belgium) was used. The inter-assay $\mathrm{CV}$ for folate content of quality-control samples was $8.3 \%(n 11)$. Recovery studies were performed by spiking the quality-control samples with FA at a level of $1 \mu \mathrm{g}$. The spiked samples underwent the entire procedure of food folate analysis (thermal extraction, tri-enzyme treatment and microbiological assay) and the percentage recovery was $93 \%$.

\section{Estimation of unmetabolised folic acid content of enriched eggs}

The microbiological assay with $L$. casei described above cannot distinguish between the different folate derivatives, so in order to estimate the unmetabolised FA content of enriched eggs (following thermal extraction with tri-enzyme treatment; Tamura ${ }^{(30)}$ ) we used two separate experimental approaches as described below. First, we estimated the FA content by measuring the amount of non-methyl folate (NMF) in all eggs collected at week 12. The basis for our estimation of FA from the NMF measurement is that regular eggs contain $>80 \%$ of folate as 5-methyltetrahydrofolate with up to $20 \%$ as NMF, all of which is present as formylfolates ${ }^{(32,33)}$. Thus, in regular eggs NMF will represent only formylfolates whereas in the enriched eggs NMF will represent the sum of formylfolates and any unmetabolised FA present. Therefore, by adjusting the NMF value of enriched eggs for the NMF value found in regular eggs, we can estimate the maximum amount of FA which could be present in enriched eggs. Our second approach used a combined HPLC/microbiological assay ${ }^{(34)}$ to directly measure the unmetabolised FA content of eggs produced at week 12 by hens fed the dietary treatments with the two highest levels of added FA.

Microbiological assay with Streptococcus faecalis (for non-methyl folate content of egg samples). This assay was conducted at Trinity College Dublin. A manuscript describing this method in detail is currently in preparation (B Blaznik, JM Scott and AM Molloy, unpublished results). Briefly, the assay was a microtitre plate adaptation of the original microbiological method described by Cooperman ${ }^{(35)}$. Calibration of the assay was performed using FA as a standard. Plates were incubated for $18 \mathrm{~h}$ at $37^{\circ} \mathrm{C}$ and turbidity at $590 \mathrm{~nm}$ was read in a microtitre plate reader. The plate reader was linked to a computer using Multiscan Ascent V1.24 software to collect data, draw a standard curve, and calculate the concentration of folate in each well. Inter- and intra-assay $\mathrm{CV}$ were $\leq 8.2 \%$. 
Combined HPLC/microbiological assay (for folic acid content of egg samples). This approach involved the separation by HPLC of FA from other folate derivatives as described in detail elsewhere ${ }^{(34)}$ with subsequent quantification of the FA fractions by microbiological assay with L. casei. This assay was performed at the University of Ulster. Briefly, the samples were spiked with $1.0 \times 10^{4} \mathrm{dpm}$ ${ }^{3}$ H-labelled FA (TRK 212; Amersham International, Little Chalfont, Bucks, UK) which served as an internal standard. Samples were injected manually onto a $250 \mathrm{~mm} \times 4.6 \mathrm{~mm}$, $5 \mu \mathrm{m}$ Supercosil LC-18 column (Supelco/Sigma-Aldrich Ltd, Gillingham, Dorset, UK). The column was eluted isocratically at $1 \mathrm{ml} / \mathrm{min}$ with the mobile phase containing sodium citrate disodium hydrogen orthophosphate buffer $(0.1 \mathrm{M})$, acetic acid $(1 \%, \mathrm{v} / \mathrm{v})$ and methanol in the ratio of 43:42:15 respectively. Six fractions in the area of FA (retention time $12.5 \mathrm{~min}$ ) were collected by an automated fraction collector (LKB FRAC-100; Pharmacia, Uppsala, Sweden). Fractions were screened for radioactivity on a scintillation counter (Wallac 1409 DSA; PerkinElmer, Waltham, MA, USA) in order to identify those containing FA. FA-containing fractions were pooled and concentrated by Waters C18 SepPak cartridges (Millpore Corp., Milford, MA, USA). The folate content of the eluate was determined by microbiological assay with L. casei $^{(29)}$ and FA calculated using the recovery figures for the original radiolabelled FA standard added to the samples (usually between 3.5 and $10 \%$ ). For quality-control purposes, extract samples prepared from reconstituted baby formula feed (SMA Gold Cap; SMA Nutrition, Dublin, Republic of Ireland) were used. The inter-assay CV of FA content of these samples was $9.1 \%(n 8)$.

\section{Statistical methods}

Statistical analysis was performed using the Statistical Package for the Social Sciences (SPSS, version 11; SPSS UK Ltd, Chertsey, Surrey, UK). ANOVA with the Scheffé post hoc test was conducted to examine the effects of treatment on egg folate and serum folate concentration. For normalisation purposes, variables were log-transformed as appropriate before statistical analysis and $P<0.05$ was considered significant. Results are expressed as mean values with their standard errors.

\section{Results}

Analysis of the various dietary treatments showed that the measured total folate content was in good agreement with the expected level calculated on the basis that the basal feed contained $1 \mathrm{mg}$ folate/ $\mathrm{kg}$ feed (Table 1).

The total folate content of the eggs produced by the hens fed each of the dietary treatments over the 12-week study period is shown in Table 2. At week 0 when all hens received the basal feed, the mean egg folate content was similar across all treatment groups, ranging from 53 to $66 \mu \mathrm{g} / 100 \mathrm{~g}$ egg. However, eggs collected from the hens fed each of the FAenhanced feeds for either 3,6 or 12 weeks had significantly higher folate levels (by 1.5 to $2 \cdot 4$-fold) than the eggs from the hens maintained on the basal feed (Table 2). No further significant increase in egg folate content was observed at an added FA level of above $16 \mathrm{mg} / \mathrm{kg}$ feed (Table 2). This plateau
Table 1. Calculated and measured total folate content $(\mathrm{mg} / \mathrm{kg}$ feed) of the dietary treatments

(Mean values with their standard errors)

\begin{tabular}{lccc}
\hline & \multicolumn{3}{c}{ Total folate content } \\
\cline { 2 - 4 } & & \multicolumn{2}{c}{ Measured $^{*}$} \\
\cline { 2 - 4 } Folic acid added to feed & Calculated $\dagger$ & Mean & SEM \\
\hline 0 & 1.0 & 1.0 & 0.1 \\
2 & 3.0 & 3.0 & 0.2 \\
4 & 5.0 & 4.7 & 0.5 \\
8 & 9.0 & 9.7 & 1.0 \\
16 & 17.0 & 13.5 & 0.7 \\
32 & 33.0 & 34.7 & 3.5 \\
\hline
\end{tabular}

*Values are the means of duplicate measurements by microbiological assay with Lactobacillus casei ${ }^{(29)}$ following thermal extraction with tri-enzyme treatment ${ }^{(30)}$. †The basal feed is formulated to provide $1 \mathrm{mg}$ folate $/ \mathrm{kg}$ feed.

effect was consistent with the observation that serum folate also reached a plateau at the doses of added FA of $16 \mathrm{mg} / \mathrm{kg}$ feed and greater (Fig. 1). Similar responses in egg folate content were noted within each treatment group irrespective of the length of time (i.e. 3-12 weeks) that the hens were fed the FA-enhanced feeds (Table 2).

The two independent methodological approaches used to estimate how much of the total folate content of egg was present as unmetabolised FA yielded similar results. Using a microbiological assay with Streptococcus faecalis (which specifically responds only to NMF), we showed that the NMF content of enriched eggs was higher than that of regular eggs; however, the NMF content of enriched eggs showed no dose effect in that it did not increase with increasing FA addition from 2 to $32 \mathrm{mg} / \mathrm{kg}$ feed (Fig. 2). We determined that NMF comprised $21 \%$ of the total folate content of regular eggs compared with $23-31 \%$ in enriched eggs (Fig. 2). Assuming that any increase in NMF (relative to total folate) was the maximum amount which could be attributed to FA, it was estimated that up to $10 \%$ of the total folate content of enriched eggs could potentially be unmetabolised FA. Using the alternative approach of direct measurement of FA based on the combined HPLC/microbiological assay, we found that the FA content of eggs produced by the hens fed the dietary treatments with the two highest doses of added FA (i.e. 16 and $32 \mathrm{mg} / \mathrm{kg}$ feed) was 3.2 (SEM 0.5 ; range $1.7-5.7$ ) and 7.5 (SEM 1.2; range $3.3-14.2) \mu \mathrm{g} / 100 \mathrm{~g}$ egg respectively (not shown). From this direct method we calculated that unmetabolised FA accounted for 2.3 and $5.1 \%$ respectively of the total folate content of the enriched eggs produced from the feeding treatments of 16 and $32 \mathrm{mg} / \mathrm{kg}$. The consistency of results between these two independent approaches to determining the FA content of enriched eggs suggests that these estimates are robust; the combination of results from both shows that FA would represent at most $10 \%$ of the total folate content of enriched eggs even at the highest FA doses.

\section{Discussion}

The results demonstrate that laying hens have the capacity to convert high doses of FA added to the feed into natural folates in their eggs. For optimal enhancement of egg folate content 
Table 2. Effect of treatment with added folic acid on egg total folate content $(\mu \mathrm{g} / 100 \mathrm{~g})^{*}$

(Mean values with their standard errors for six to eight eggs)

\begin{tabular}{|c|c|c|c|c|c|c|c|c|c|c|c|c|}
\hline & \multicolumn{2}{|c|}{0} & \multicolumn{2}{|c|}{2} & \multicolumn{2}{|c|}{4} & \multicolumn{2}{|c|}{8} & \multicolumn{2}{|c|}{16} & \multicolumn{2}{|c|}{32} \\
\hline & Mean & SEM & Mean & SEM & Mean & SEM & Mean & SEM & Mean & SEM & Mean & SEM \\
\hline Week 0† & $56 \cdot 1$ & $5 \cdot 8$ & $60 \cdot 9$ & 4.0 & $53 \cdot 3$ & $6 \cdot 4$ & 59.4 & $3 \cdot 6$ & $61 \cdot 0$ & 3.6 & $66 \cdot 2$ & 4.8 \\
\hline Week 3 & $70 \cdot 0^{\mathrm{a}}$ & 4.3 & $108 \cdot 2^{b}$ & $2 \cdot 8$ & $101.5^{\mathrm{b}}$ & $5 \cdot 2$ & $123 \cdot 1^{\mathrm{b}}$ & 4.8 & $147 \cdot 2^{\mathrm{c}}$ & 4.5 & $165.7^{c}$ & 6.0 \\
\hline Week 6 & $64.5^{\mathrm{a}}$ & 3.9 & $103 \cdot 1^{\mathrm{b}}$ & 6.5 & $99 \cdot 7^{b}$ & 6.8 & $125 \cdot 3^{\mathrm{b}, \mathrm{c}}$ & 6.4 & $157 \cdot 6^{c}$ & 6.0 & $156 \cdot 6^{\mathrm{c}}$ & $10 \cdot 9$ \\
\hline Week 12 & $60.0^{\mathrm{a}}$ & $2 \cdot 0$ & $96 \cdot 8^{\mathrm{b}, \mathrm{c}}$ & $3 \cdot 1$ & $90 \cdot 7^{b}$ & 7.9 & $122 \cdot 2^{\mathrm{c}}$ & 4.7 & $144 \cdot 6^{d}$ & 5.9 & $131.9^{d}$ & 6.8 \\
\hline
\end{tabular}

a,b,c,d Mean values within a same row with unlike superscript letters were significantly different $(P<0.05$; ANOVA with Scheffé post hoc test on log-transformed data where applicable).

*Values are means of duplicate measurements by microbiological assay with Lactobacillus casei ${ }^{(29)}$ following thermal extraction with tri-enzyme treatment ${ }^{(30)}$.

†All hens received the basal feed which was formulated to provide $1 \mathrm{mg}$ folate $/ \mathrm{kg}$ feed.

(i.e. $150 \mu \mathrm{g} / 100 \mathrm{~g}$ egg; $2 \cdot 3$-fold higher than a regular egg), a FA level of $16 \mathrm{mg} / \mathrm{kg}$ needs to be added to the basal feed. Importantly we show that at this feeding dose, the FA content represents no more than $10 \%$ of the total folate content of the enriched egg.

Our findings support previous studies ${ }^{(26-28)}$ which showed that it is feasible to produce eggs with an enriched total folate content by the addition of FA to the feed of laying hens. Consistent with these studies, we demonstrate that the addition of a small dose of FA to feed $(2 \mathrm{mg} / \mathrm{kg})$ can result in a significant increase in egg folate content. However, the

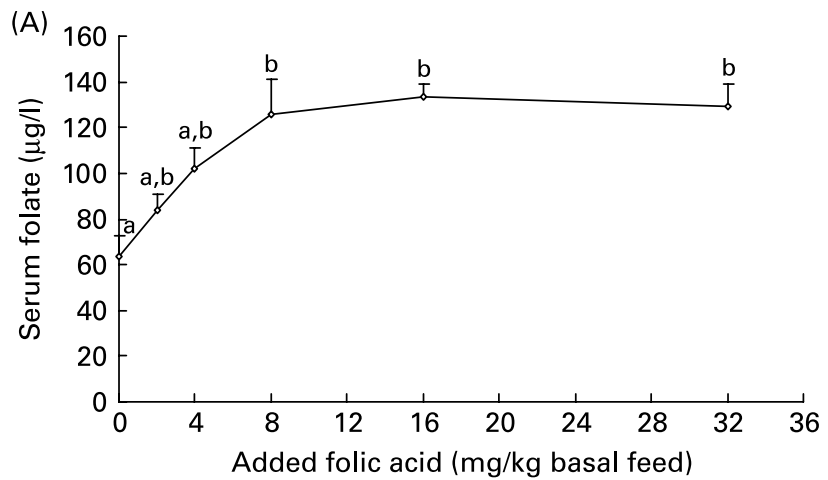

(B)

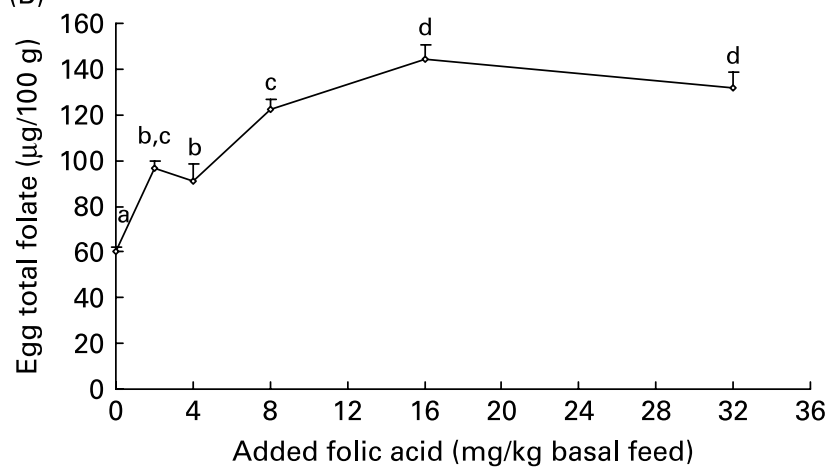

Fig. 1. The effect of 12 weeks of dietary treatment with added folic acid $(0-32 \mathrm{mg} / \mathrm{kg}$ basal feed) on serum folate $(\mathrm{A})$ and egg total folate content $(\mathrm{B})$ of laying hens. Values are means for duplicate measurements by microbiological assay with Lactobacillus casei ${ }^{(29)}$ with their standard errors represented by vertical bars ( $n$ 6-8 for serum values; $n 7-8$ for egg values). The basal feed was formulated to provide $1 \mathrm{mg}$ folate/kg feed. ${ }_{a, b, c, d}$ Mean values with unlike letters were significantly different $(P<0.05$; ANOVA with Scheffé post hoc test). optimal dose required to achieve a maximal egg total folate content was found to be $16 \mathrm{mg} / \mathrm{kg}$, four-fold higher than previously reported, although a higher egg folate content was produced at this dose in the present study compared with equivalent doses used in other studies ${ }^{(27,28)}$. The discrepancy between studies may be the result of an insufficient range and number of FA doses added to the feed ${ }^{(26)}$, variability in feed intake as hens were fed ad libitum and/or the use of different strains of hens. Another important factor is the use of different analytical procedures for the determination of egg folate content. We measured total folate in the whole egg whereas the methodology of previous studies ${ }^{(27,28)}$ was based on the measurement in egg yolk of the 5-methyltetrahydrofolate content only. Although it is true that 5-methyltetrahydrofolate is the predominant form representing $>80 \%$ of the folate content of eggs ${ }^{(32,33,36)}$, up to $20 \%$ is present as NMF (specifically formylfolates; McKillop et al. ${ }^{(32)}$; Vahteristo et al. ${ }^{(33)}$ ). Thus, by measuring the 5-methyltetrahydrofolate fraction only, some of the previous studies may have underestimated the total folate content of the enriched eggs.

Analysis of unmetabolised FA was a novel aspect of the present paper which was not addressed in any of the previous studies in this area ${ }^{(26-28)}$. Using two independent approaches for determining the FA content of enriched eggs, we showed that FA would represent at most $10 \%$ of the total folate

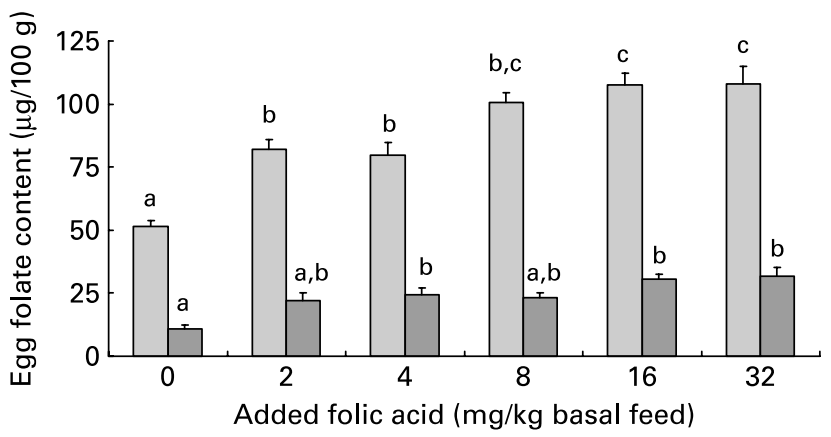

Fig. 2. Total folate ( $\square$ ) and non-methyl folate ( $\square$ ) content of eggs after 12 weeks of dietary treatment. Values are means for six to eight eggs, with their standard errors represented by vertical bars. The basal feed was formulated to provide $1 \mathrm{mg}$ folate/kg feed. Total folate content was analysed by microbiological assay with Lactobacillus casei ${ }^{(29)}$. Non-methyl folate content was analysed by microbiological assay with Streptococcus faecalis. ${ }^{a, b, c}$ Within each assay, mean values with unlike letters were significantly different $(P<0.05$; ANOVA with Scheffé post hoc test on log-transformed data where applicable) 
content of enriched eggs even at the highest FA feeding doses (i.e. 16 and $32 \mathrm{mg} / \mathrm{kg}$ feed). The finding that the enhanced folate content of enriched eggs is predominantly (over 90\%) natural folates demonstrates that the FA in the feed (even at doses of $32 \mathrm{mg} / \mathrm{kg}$ ) can be converted by the hen into the natural forms of the vitamin which are present in the egg for human consumption. Furthermore, although a FA content of up to $10 \%$ was detected in the folate-enriched eggs, the concentration was low (i.e. $8 \mu \mathrm{g} / \mathrm{egg}$ for an average-sized egg; Food Standards Agency ${ }^{(37)}$, a level of ingestion well below the threshold for humans at which unmetabolised FA starts to appear in the circulation when the capacity of intestinal cells to reduce FA is exceeded ${ }^{(38)}$. Therefore, the consumption of folate-enriched eggs will not expose the consumer to the potential risks that are sometimes associated with high intakes of $\mathrm{FA}^{(24,25)}$, especially in populations already exposed to higher FA intakes through fortification and/or supplements.

The folate enrichment of eggs described here results in an increase in the folate content of an average-sized egg from $32 \mu \mathrm{g}$ to $75 \mu \mathrm{g}$. The recommended folate intake for adults varies considerably among countries ranging from $200 \mu \mathrm{g} / \mathrm{d}$ in some European countries to $400 \mu \mathrm{g} / \mathrm{d}$ in the USA and other European countries. Based on these official recommendations, we calculated that the daily consumption of just one folate-enriched egg would provide the consumer with 19 to $38 \%$ of recommended intakes; however, depending on dietary practices a portion of egg is often greater than one egg (for example, scrambled or omelette; Food Standard Agency ${ }^{(37)}$ ), thereby offering higher folate intakes to such consumers. Furthermore, the conversion of high-dose FA in feed to natural folates as described here in hens could be extended to other animals to potentially produce a range of novel foods enriched with natural folates. The provision of such foods could be particularly beneficial to the many countries without mandatory FA fortification policies in place, including some that do not even permit it on a voluntary basis (i.e. at the manufacturer's discretion). The latter countries are unlikely to introduce FA fortification in the near future; therefore, identifying novel strategies to improve folate status is a matter of urgency because alternative approaches to reducing the risk of neural tube defects to date (based on promoting FA supplements periconceptionally) have proven to be ineffective ${ }^{(12,15)}$.

Regular consumption of folate-enriched egg could also be of benefit to the general population in lowering plasma homocysteine and thus potentially CVD. In particular, there is good evidence that enhanced folate status is beneficial in the primary prevention of stroke ${ }^{(4,21)}$. However, folate intakes in general appear to be suboptimal in many European countries, with homocysteine levels generally much higher ${ }^{(39,40)}$ than those associated with the lowest risk of stroke ${ }^{(4,21)}$. Likewise, typical dietary folate intakes in European women are well below the level associated with the lowest risk of breast cancer $^{(6)}$. Against a background of low dietary folate intake and no contribution from fortified foods or supplements, it would appear that even small increases (i.e. as little as $50 \mu \mathrm{g} / \mathrm{d})$ are associated with significant reductions in disease risk $^{(6)}$. Thus, the introduction of novel products such as folate-enriched eggs could have greatest impact in these countries.

Based on an enrichment level of $16 \mathrm{mg} \mathrm{FA} / \mathrm{kg}$ feed, the production costs associated with folate-enriched eggs are minimal (approximately $£ 0.20$ per $1000 \mathrm{~kg}$ feed or less than $1 \mathrm{p}$ per egg). Furthermore, the duration of $\mathrm{FA}$ feeding required to achieve an optimal egg folate content is short (i.e. within 3 weeks), making enriched eggs a cost-effective option for increasing folate intakes particularly in nutritionally vulnerable groups, such as those of lower socio-economic status. In fact, data from the US National Health and Nutrition Examination Survey (NHANES) showed that egg consumers were more likely to be older adults and those with a fewer number of years spent in education ${ }^{(41)}$. In addition, although we did not measure the stability of folate in enriched eggs during cooking, our previous investigation of this aspect suggested that unlike folate from vegetable sources, where losses of up to $55 \%$ can occur depending on the method of cooking, folates in animal products were generally stable during common methods of cooking ${ }^{(31)}$. Furthermore, we anticipate that the bioavailability of folate from enriched eggs would be similar to that from other food folate sources such as green vegetables ${ }^{(42)}$. In addition, folate-enriched egg would be unlikely to meet the same degree of consumer opposition as other functional foods that have been investigated to increase folate intake. For example, plants have been genetically modified very successfully to produce high folate levels, but consumer reluctance to accept GM foods means that they are unlikely to offer a viable means of enhancing folate intakes generally ${ }^{(43)}$. Although in the past public health bodies recommended that consumers limit their egg intake on the basis of their high cholesterol content (and the general perception that dietary cholesterol increased serum cholesterol concentrations), the latest evidence suggests that egg consumption up to six times per week is not associated with an increased risk of heart disease ${ }^{(44)}$. Thus, the folateenriched eggs described here can be considered a viable option from a practical standpoint, given the low production costs and probable acceptability by both consumers and health professionals.

In summary, the present paper demonstrates that high-dose FA in feed is converted by hens into natural egg folates, with a dose of $16 \mathrm{mg} / \mathrm{kg}$ achieving maximal folate enrichment with minimal $(<10 \%)$ FA content. The daily consumption of this novel food would offer consumers a practical means of increasing folate intake (and potentially protecting against disease), particularly for populations with limited or no access to FA-fortified foods. In addition, folate-enriched eggs and other novel foods produced in this way could offer a cost-effective alternative without the safety concerns relating to FA-fortified foods. These findings are particularly relevant to the current debate in the UK and elsewhere regarding strategies to increase folate status. Further investigation is required to confirm the effectiveness of consuming folate-enriched eggs on biomarkers of folate status in humans.

\section{Acknowledgements}

The present study was supported by Invest Northern Ireland (Proof of Concept Scheme). H. McN., J. M. S., E. M. E. McC., K. J. McC. and K. P. designed the study. E. M. E. McC. managed the feeding study and collected samples. L. H., B. B. M., A. M. M., C. G. and K. P. were responsible for laboratory analysis. L. H. carried out the statistical analysis 
and H. McN., J. M. S. and K. P. interpreted the results. L. H., H. McN., J. M. S. and K. P. were responsible for writing the manuscript and comments from all other authors were included in the final draft. None of the authors had any financial or personal interests, including advisory board affiliations, in any company or organisation sponsoring the research.

\section{References}

1. Anonymous (1991) Prevention of neural tube defects: results of the Medical Research Council Vitamin Study. MRC Vitamin Study Research Group. Lancet 338, 131-137.

2. Czeizel AE \& Dudas I (1992) Prevention of the first occurrence of neural-tube defects by periconceptional vitamin supplementation. $N$ Engl J Med 327, 1832-1835.

3. Wald DS, Law M \& Morris JK (2002) Homocysteine and cardiovascular disease: evidence on causality from a meta-analysis. BMJ 325, 1202-1206

4. Wang X, Qin X, Demirtas H, Li J, Mao G, Huo Y, Sun N, Liu L \& Xu X (2007) Efficacy of folic acid supplementation in stroke prevention: a meta-analysis. Lancet 369, 1876-1882.

5. Kim Y-I (1999) Folate and carcinogenesis: evidence, mechanisms, and implications. $J$ Nutr Biochem 10, 66-88.

6. Ericson U, Sonestedt E, Gullberg B, Olsson H \& Wirfalt E (2007) High folate intake is associated with lower breast cancer incidence in postmenopausal women in the Malmo Diet and Cancer cohort. Am J Clin Nutr 86, 434-443.

7. Selhub J, Bagley LC, Miller J \& Rosenberg IH (2000) B vitamins, homocysteine and neurocognitive function in the elderly. Am J Clin Nutr 71, 614S-620S.

8. Reynolds E (2006) Vitamin $\mathrm{B}_{12}$, folic acid and the nervous system. Lancet Neurol 5, 949-960.

9. McLean RR, Jacques PF, Selhub J, Tucker KL, Samelson EJ, Broe KE, Hannan MT, Cupples LA \& Kiel DP (2004) Homocysteine as a predictive factor for hip fractures in older persons. N Engl J Med 350, 2042-2049.

10. Van Meurs JBJ, Dhonukshe-Rutten RAM, Pluijm SMF, et al. (2004) Homocysteine levels and the risk of osteoporotic fracture. N Engl J Med 350, 2033-2041.

11. Centers for Disease Control and Prevention (1992) Recommendations for the use of folic acid to reduce the number of cases of spina bifida and other neural tube defects. Morb Mortal Wkly Rep 41, 1-7.

12. Busby A, Armstrong B, Dolk H, et al. (2005) Preventing neural tube defects in Europe: a missed opportunity. Reprod Toxicol 20, 393-402.

13. Eichholzer M, Tonz O \& Zimmermann R (2006) Folic acid: a public-health challenge. Lancet 367, 1352-1361.

14. Green-Raleigh K, Carter H, Mulinare J, Prue C \& Petrini J (2006) Trends in folic acid awareness and behaviour in the United States: the Gallup Organization for the March of Dimes Foundation surveys, 1995-2005. Matern Child Health $J$ 10, S177-S182.

15. Botto LD, Lisi A, Robert-Gnansia E, et al. (2005) International retrospective cohort study of neural tube defects in relation to folic acid recommendations: are the recommendations working? BMJ 330, 571-576.

16. Jacques PF, Selhub J, Bostom AG, Wilson PWF \& Rosenberg IH (1999) The effect of folic acid fortification on plasma folate and total homocysteine concentrations. $N$ Engl J Med 340, 1449-1454.

17. Pfeiffer CM, Caudill SP, Gunter EW, Osterloh J \& Sampson EJ (2005) Biochemical indicators of B vitamin status in the US population after folic acid fortification: results from the National Health and Nutrition Examination Survey 1999-2000. Am J Clin Nutr 82, 442-450.
18. Honein MA, Paulozzi LJ, Mathews TJ, Erickson JD \& Wong L-YC (2001) Impact of folic acid fortification of the US food supply on the occurrence of neural tube defects. JAMA $\mathbf{2 8 5}$, 2981-2986.

19. Castilla EE, Orioli IM, Lopez-Camelo JS, da Graca Dutra M \& Nazer-Herrera J (2003) Preliminary data on changes in neural tube defect prevalence rates after folic acid fortification in South America. Am J Med Genet 123A, 123-128.

20. De Wals P, Tairou F, Van Allen MI, et al. (2007) Reduction in neural-tube defects after folic acid fortification in Canada. $N$ Engl J Med 357, 135-142.

21. Yang Q, Botto LD, Erickson JD, Berry RJ, Sambell C, Johansen $\mathrm{H}$ \& Friedman JM (2006) Improvement in stroke mortality in Canada and the United States, 1990 to 2002. Circulation 113, $1335-1343$.

22. Scientific Advisory Committee on Nutrition (2006) Folate and Disease Prevention. London: The Stationery Office, http:// www.sacn.gov.uk/reports/\#

23. Food Standards Agency (2007) Board updated on folic acid and trans fats. http://www.food.gov.uk/news/newsarchive/2007/oct/ updatefolatetransfats

24. Cole BF, Baron JA, Sandler RS, et al. (2007) Folic acid for the prevention of colorectal adenomas: a randomized clinical trial. JAMA 297, 2351-2359.

25. Dickinson CJ (1995) Does folic acid harm people with vitamin $\mathrm{B}_{12}$ deficiency? Q J Med 88, 357-364.

26. Sherwood TA, Alphin RL, Saylor WW \& White HB III (1993) Folate metabolism and deposition in eggs by laying hens. Arch Biochem Biophys 307, 66-72.

27. House JD, Braun K, Ballance DM, O'Connor CP \& Guenter W (2002) The enrichment of eggs with folic acid through supplementation of the laying hen diet. Poult Sci 81, 1332-1337.

28. Hebert K, House JD \& Guenter W (2005) Effect of dietary folic acid supplementation on egg folate content and the performance and folate status of two strains of laying hens. Poult Sci 84, 1533-1538.

29. Molloy AM \& Scott JM (1997) Microbiological assay for serum, plasma and red cell folate using cryopreserved, microtiter plate method. Methods Enzymol 281, 43-53.

30. Tamura T (1998) Determination of food folate. J Nutr Biochem 9, 285-293.

31. McKillop DJ, Pentieva K, Daly D, McPartlin JM, Hughes J, Strain JJ, Scott JM \& McNulty H (2002) The effect of different cooking methods on folate retention in various foods that are amongst the major contributors to folate intake in the UK diet. BJN 88, 681-688.

32. McKillop DJ, Pentieva KD, Scott JM, Strain JJ, McCreedy R, Alexander J, Patterson K, Hughes J \& McNulty H (2003) Protocol for the production of concentrated extracts of food folate for use in human bioavailability studies. J Agric Food Chem 51, 4382-4388.

33. Vahteristo LT, Ollilainen V \& Varo P (1997) Liquid chromatographic determination of folate monoglutamates in fish, meat, egg and dairy products consumed in Finland. J AOAC Int 80, 373-378.

34. Kelly P, McPartlin J \& Scott JM (1996) A combined highperformance liquid chromatographic-microbiological assay for serum folic acid. Anal Biochem 238, 179-183.

35. Cooperman JM (1972) Assay for folic acid activity in blood. Analyt Microbiol 2, 439-456.

36. Seyoum E \& Selhub J (1998) Properties of food folates determined by stability and susceptibility to intestinal pteroylpolyglutamate hydrolase action. J Nutr 128, 1956-1960.

37. Food Standards Agency (2002) Food Portion Sizes, 3rd ed. London: The Stationery Office.

38. Sweeney MR, McPartlin J \& Scott J (2007) Folic acid fortification and public health: report on threshold doses above which unmetabolized folic acid appears in serum. BMC Public Health 7, 41-47. 
39. Alfthan G, Laurinen MS, Valsta LM, Pastinen T \& Aro A (2003) Folate intake, plasma folate and homocysteine status in a random Finnish population. Eur J Clin Nutr 57, 81-88.

40. Berstad P, Konstantinova SV, Refsum H, Nurk E, Vollset SE, Tell GS, Ueland PM, Drevon CA \& Ursin G (2007) Dietary fat and plasma total homocysteine concentrations in 2 adult age groups: the Hordaland Homocysteine study. Am J Clin Nutr 85, 1598-1605.

41. Song WO \& Kerver JM (2000) Nutritional contribution of eggs to American diets. J Am Coll Nutr 19, Suppl. 5, 556S-562S.
42. McKillop DJ, McNulty H, Scott JM, et al. (2006) The rate of intestinal absorption of natural food folates is not related to the extent of folate conjugation. Am J Clin Nutr 84, 167-173.

43. Diaz de la Garza RI, Gregory JF III \& Hanson AD (2007) Folate biofortification of tomato fruit. Proc Natl Acad Sci U S A 104, 4218-4222.

44. Djousse L \& Gaziano JM (2008) Egg consumption and risk of heart failure in the Physicians' Health Study. Circulation 117, $512-516$. 